\title{
ANALISIS PENGARUH MANAJEMEN LABA TERHADAP NILAI PERUSAHAAN DENGAN GOOD CORPORATE GOVERNANCE SEBAGAI VARIABEL MODERASI (STUDI KASUS PADA PERUSAHAAN MANUFAKTUR YANG TERDAFTAR DI BURSA EFEK INDONESIA TAHUN 2015-2017)
}

\author{
Theresia Shirley Tanadi \\ Program Studi Magister Manajemen Universitas Tarumanagara \\ shirleytanadi@gmail.com \\ Indra Widjaja \\ Program Studi Magister Manajemen Universitas Tarumanagara
}

\begin{abstract}
The main objective of this research is to collect the empirical evidence of the influence of earnings management to the Firms' value, with good corporate governance as the moderating variable, for Manufacturing Firms that are registered to the Indonesian Stock Exchange as of 2015 - 2017. Manufacturing Firms as the research subject, with Consumer Goods Industry and Basic Industry \& Chemical sector. The research variables are (1) profit management, with proxy discretionary accruals modified jones; (2) Firm's value, with proxy price to book value; and (3) good corporate governance, with proxy independent commissioner proportion and audit committee. This research used simple and moderated regression analysis method. The result indicates that earnings management has an impact on the Firms' value and audit committee moderates the influence of earnings management to Firms' value, whereas independent commissioner does not.
\end{abstract}

Keywords : Earnings Management, Firm Value, Good Corporate Governance

\begin{abstract}
Abstrak : Tujuan utama penelitian ini adalah untuk memperoleh bukti empiris pengaruh manajemen laba terhadap nilai perusahaan, dengan good corporate governance sebagai variabel moderasi, pada perusahaan manufaktur yang terdaftar di Bursa Efek Indonesia tahun 2015-2017. Perusahaan manufaktur sebagai subjek penelitian, dengan sektor Consumer Goods Industry dan Basic Industry \& Chemical. Variabel-variabel dalam penelitian ini yaitu (1) manajemen laba, dengan proxy discretionary accruals modified jones; (2) nilai perusahaan, dengan proxy price to book value; dan (3) good corporate governance, dengan proxy proporsi komisaris independen dan komite audit. Penelitian ini menggunakan metode analisis regresi sederhana dan regresi moderasi. Hasil penelitian menunjukkan bahwa manajemen laba memiliki pengaruh terhadap nilai perusahaan dan komite audit memoderasi pengaruh manajemen laba terhadap nilai perusahaan. Sedangkan komisaris independen tidak memoderasi pengaruh manajemen laba terhadap nilai perusahaan.
\end{abstract}

Kata Kunci : Manajemen Laba, Nilai Perusahaan, Good Corporate Governance.

\section{PENDAHULUAN}

Pada SFAS No. 1 mencantumkan fokus utama pelaporan keuangan adalah informasi kinerja perusahaan yang ditunjukkan dari informasi laba dan komponennya, tujuan utamanya memberikan informasi yang berguna bagi mereka yang paling berkepentingan (stakeholder) dalam laporan keuangan. Untuk itu, salah satu strategi yang dilakukan manajemen dalam penyusunan laporan keuangan melalui manajemen laba. Melalui manajemen laba, diharapkan nilai perusahaan dapat meningkat. Pada praktik manajemen laba, dapat menimbulkan dampak positif dan negatif. Masalah terkait praktik ini yaitu masalah keagenan (agency theory). 
Menurut Surifah (2017) dan Indriani (2014), praktik manajemen laba mempengaruhi nilai perusahaan, dengan pengaruh beberapa proxy GCG yang memoderasi. Hal ini bertentangan dengan hasil penelitian Darwis (2012) dan Kamil 2014. Hasil penelitian yang tidak konsisten tersebut menjadi latar belakang penulis melakukan penelitian ini.

\section{TELAAH KEPUSTAKAAN}

Manajemen laba atau earning management adalah the choice by a manager of accounting policies, or actions affecting earnings, so as to achieve some specific reported earnings objective (Scott, 2015). Pola-pola tindakan manajemen laba terdiri dari (1) taking a bath, dilakukan agar laba periode berikutnya menjadi lebih tinggi dari seharusnya; (2) income maximization, dilakukan agar laba periode sekarang menjadi lebih tinggi dari seharusnya; (3) income minimization, dilakukan agar laba periode sekarang menjadi lebih rendah dari yang seharusnya, dan (4) income smoothing, dilakukan dengan melakukan perataan laba (menaikkan atau menurunkan) untuk menghindari fluktuasi yang beresiko tinggi.

Price to Book Value (PBV) merupakan salah satu cara dalam rasio nilai pasar, yang akan menggambarkan kondisi nilai perusahaan pada pasar secara umum, dibandingkan dengan perusahaan lain (Fahmi, 2014). PBV digunakan oleh penasihat investasi, investor, dan manajer keuangan untuk membandingkan nilai pasar perusahaan dengan nilai buku. PBV mengindikasikan seberapa banyak pemegang saham membayar net asset dari perusahaan (Marangu dan Jangongo, 2014).

The Indonesian Institute for Corporate Governance (IICG) mendefinisikan good corporate governance (GCG) sebagai proses dan struktur yang diterapkan dalam menjalankan perusahaan, dengan tujuan utama meningkatkan nilai pemegang saham dalam jangka panjang, dengan tetap memperhatikan kepentingan pihak petaruh lainnya (Hamdani, sebagaimana dikutip dari Khomsiyah, 2005). Konsep GCG ini muncul karena adanya pemisahaan kepemilikan dalam perusahaan dan permasalahan tersebut disebabkan ada perbedaan kepentingan antara agen dan principal sebagai pelaku utama perusahaan, atau dikenal dengan istilah agency problem. Mekanisme GCG diharapkan dapat menyelaraskan (alignment) kepentingan antara manajemen sebagai agen dan pemilik sebagai principal. Hal ini juga dapat membantu terciptanya hubungan kondusif dan dapat dipertanggungjawabkan antara dewan komisaris, dewan direksi, dan pemegang saham, dalam rangka meningkatkan kinerja perusahaan.

\section{METODOLOGI PENELITIAN}

Subjek penelitian yaitu perusahaan manufaktur go public yang terdaftar di Bursa Efek Indonesia (BEI) pada tahun 2015-2017, yang terdiri dari sektor Consumer Goods Industry dan Basic Industry and Chemical. Total subjek penelitian sebanyak 43 perusahaan. Objek penelitian terdiri dari 3 jenis, yaitu (1) manajemen laba sebagai variabel bebas; (2) nilai perusahaan sebagai variabel terikat; dan (3) good corporate governance sebagai variabel moderasi.

Metode analisis data dalam penelitian ini yaitu melalui uji statistik deskriptif variabel, uji asumsi klasik, uji koefisien determinasi, uji regresi sederhana, uji regresi moderasi, uji kelayakan model (uji F), dan uji koefisien regresi parsial (uji T). Pengujian dilakukan melalui SPSS versi 22.

Berdasarkan metode analisis tersebut, hipotesis (Ha) yang akan diuji yaitu:

Ha1 : manajemen laba berpengaruh terhadap nilai perusahaan

Ha2 : komisaris independen memoderasi pengaruh manajemen laba terhadap nilai perusahaan

Ha3 : komite audit memoderasi pengaruh manajemen laba terhadap nilai perusahaan 


\section{ANALISIS DAN BAHASAN TEMUAN}

Pengujian pertama yang dilakukan yaitu uji normalitas, dengan uji statistik nonparametrik Kolmogorov-Smirnov (K-S). Hasil pengujian ini adalah sebagai berikut:

\begin{tabular}{|c|c|c|}
\hline \multicolumn{3}{|c|}{ One-Sample Kolmogorov-Smirnov Test } \\
\hline & & $\begin{array}{l}\text { Unstandardiz } \\
\text { ed Residual }\end{array}$ \\
\hline $\mathrm{N}$ & & 93 \\
\hline \multirow{2}{*}{ Normal Parameters ${ }^{a, b}$} & Mean & .0000000 \\
\hline & Std. Deviation & 1.22431856 \\
\hline Most Extreme & Absolute & .128 \\
\hline \multirow[t]{2}{*}{ Dif $f$ erences } & Positive & .128 \\
\hline & Negative & -.069 \\
\hline Kolmogorov-Smirnov Z & & 1.233 \\
\hline Asy mp. Sig. (2-tailed) & & .096 \\
\hline
\end{tabular}

Berdasarkan tabel di atas, nilai asymp. Sig. (2-tailed) yaitu 0,096. Nilai ini lebih besar dari 0,05 , apabila dibandingkan dengan kriteria yang ada, dan disimpulkan bahwa data dalam penelitian terdistribusi normal.

Pengujian kedua yaitu uji autokorelasi melalui uji Durbin-Watson. Hasil pengujian sebagai berikut:

Model Summary
\begin{tabular}{|l|r|r|r|r|r|}
\hline Model & R & R Square & $\begin{array}{c}\text { Adjusted } \\
\text { R Square }\end{array}$ & $\begin{array}{c}\text { Std. Error of } \\
\text { the Estimate }\end{array}$ & $\begin{array}{c}\text { Durbin- } \\
\text { Watson }\end{array}$ \\
\hline 1 & $.435^{\mathrm{a}}$ & .189 & .143 & 1.25901 & 2.181 \\
\hline
\end{tabular}
a. Predictors: (Constant), Manajemen Laba* Komite Audit, Komisaris
Independen, Komite Audit, Manajemen Laba*Komisaris Independen,
Manajemen Laba
b. Dependent Variable: Nilai Perusahaan

Berdasarkan tabel di atas, nilai DW yaitu 2,181. Sehingga, apabila nilai tersebut dimasukkan ke dalam kriteria DW, diperoleh perbandingan sebagai berikut:

$\mathrm{du}<\mathrm{DW}<4$-du $\rightarrow 1,78<2,181<2,22$

Kesimpulan dari pengujian autokorelasi dengan pengukuran Durbin-Watson yaitu tidak ada autokorelasi dan model regresi dapat dikatakan layak.

Pengujian ketiga yaitu uji multikolinearitas melalui nilai tolerance dan Variance Inflation Factor (VIF). Hasil pengujian sebagai berikut:

\begin{tabular}{|c|c|c|c|}
\hline \multicolumn{4}{|c|}{ Coefficients ${ }^{a}$} \\
\hline \multirow[b]{2}{*}{ Model } & & \multicolumn{2}{|c|}{ Collinearity Statistics } \\
\hline & & Tolerance & VIF \\
\hline \multirow[t]{3}{*}{$\overline{1}$} & Manajemen Laba & .976 & 1.025 \\
\hline & Komisaris Independen & .985 & 1.015 \\
\hline & Komite Audit & .976 & 1.025 \\
\hline
\end{tabular}

a. Dependent Variable: Nilai Perusahaan

Tabel di atas menunjukkan masing-masing variabel independen, nilai tolerance lebih dari 0,1 dan nilai VIF kurang dari 10, maka dapat disimpulkan tidak terjadi multikolinearitas.

Pengujian keempat yaitu uji heterokedastisitas melalui Glejser, dengan kriteria apabila salah satu variabel bernilai lebih kecil dari 0,05 maka terjadi heterokedastisitas. Hasil pengujian sebagai berikut:

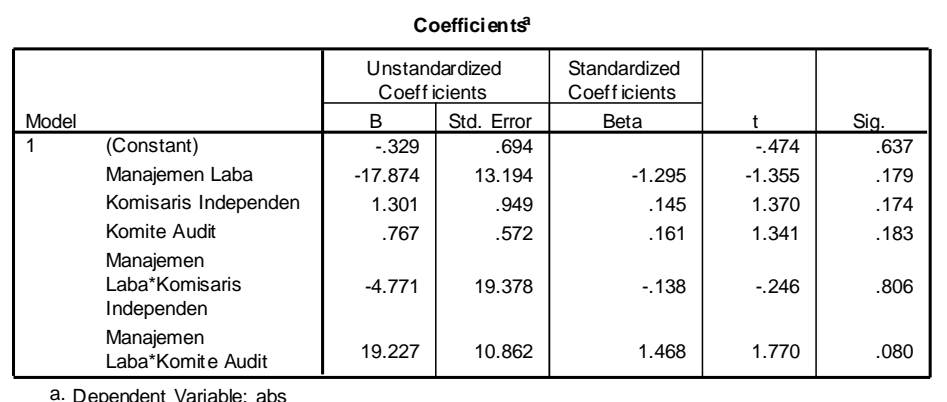

a. Dependent Variable: abs 
Tabel di atas menunjukkan nilai sig. pada masing-masing pada variabel independen dan apabila dibandingkan dengan kriteria, dapat disimpulkan variabel independen yang digunakan dalam model regresi tidak mengalami heterokedastisitas.

Pengujian kelima yaitu uji koefisien determinasi $\left(\mathrm{R}^{2}\right)$ dan terbagi menjadi 2. Uji koefisien determinasi $\left(\mathrm{R}^{2}\right)$ yang pertama terkait dengan model regresi sederhana untuk Ha1, dengan hasil uji sebagai berikut:

\begin{tabular}{|c|c|c|c|c|}
\hline \multicolumn{5}{|c|}{ Model Summary } \\
\hline Model & $\mathrm{R}$ & R Square & $\begin{array}{l}\text { Adjusted } \\
\text { R Square }\end{array}$ & $\begin{array}{l}\text { Std. Error of } \\
\text { the Estimate }\end{array}$ \\
\hline 1 & $.213^{a}$ & .045 & .035 & 1.33591 \\
\hline
\end{tabular}

a. Predictors: (Constant), Manajemen Laba

Tabel di atas menunjukkan bahwa, adjusted $R^{2}$ sebesar 0,035 , yang artinya manajemen laba dapat menjelaskan nilai perusahaan sebesar 0,035 atau sebesar 3,5\%.

Uji koefisien determinasi $\left(\mathrm{R}^{2}\right)$ yang kedua terkait model regresi moderasi untuk Ha2 dan $\mathrm{Ha} 3$, dengan hasil uji sebagai berikut:

\begin{tabular}{l} 
Model Summary \\
\begin{tabular}{|l|c|c|c|c|}
\hline Model & R & R Square & $\begin{array}{c}\text { Adjusted } \\
\text { R Square }\end{array}$ & $\begin{array}{c}\text { Std. Error of } \\
\text { the Estimate }\end{array}$ \\
\hline 1 & $.435^{\mathrm{a}}$ & .189 & .143 & 1.25901 \\
\hline
\end{tabular} \\
\hline \\
a. Predictors: (Constant), Manajemen Laba*Komite Audit, \\
Komisaris Independen, Komite Audit, Manajemen \\
Laba*Komisaris Independen, Manajemen Laba
\end{tabular}

Tabel di atas menunjukkan nilai adjusted $R^{2}$ sebesar 0,143 , yang artinya variabel manajemen laba dapat menjelaskan nilai perusahaan dengan semakin baik dengan adanya interaksi dari komisaris independen dan komite audit. Hal ini dibuktikan dengan nilai adjusted $R^{2}$ sebesar 0,143 atau $14.3 \%$.

Pengujian keenam dan ketujuh yaitu uji regresi sederhana dan uji regresi moderasi, dan diperoleh persamaan sebagai berikut:

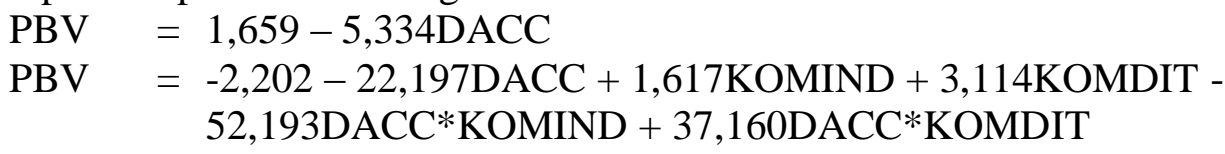

Pengujian kedelapan yaitu uji kelayakan model (uji F), dengan kriteria apabila nilai sig. $<0,05$ maka Ha diterima. Hasil uji F sebagai berikut:

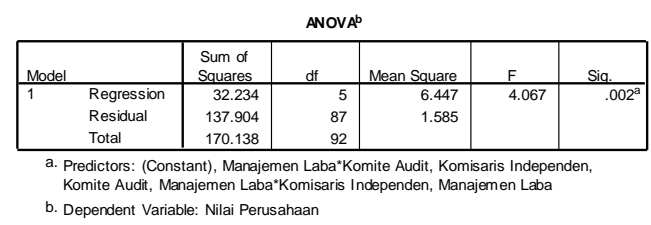

Tabel di atas menunjukkan nilai sig. sebesar 0,002, dan apabila dimasukkan ke dalam kriteria yang ada, nilai sig. tersebut lebih kecil dari 0,05, yang artinya Ha diterima. Variabel independen yang ada dalam penelitian secara simultan memengaruhi nilai perusahaan.

Pengujian kesembilan yaitu uji koefisien regresi parsial (uji T), dengan kriteria apabila nilai sig. < 0,05 maka Ha diterima. Hasil uji T pertama untuk Ha1 yaitu:

\begin{tabular}{|c|c|c|c|c|c|c|}
\hline \multicolumn{7}{|c|}{ Coefficients $^{\mathrm{a}}$} \\
\hline \multirow[b]{2}{*}{ Model } & & \multicolumn{2}{|c|}{$\begin{array}{l}\text { Unstandardized } \\
\text { Coeff icients }\end{array}$} & \multirow{2}{*}{$\begin{array}{c}\begin{array}{c}\text { Standardized } \\
\text { Coeff icients }\end{array} \\
\text { Beta }\end{array}$} & \multirow[b]{2}{*}{$t$} & \multirow[b]{2}{*}{ Sig. } \\
\hline & & B & Std. Error & & & \\
\hline & (Constant) & 1.659 & .139 & & 11.961 & .000 \\
\hline & Manajemen Laba & -5.334 & 2.562 & -.213 & -2.082 & .040 \\
\hline
\end{tabular}

Tabel di atas menunjukkan nilai sig. sebesar 0,04, maka Ha diterima atau manajemen laba berpengaruh terhadap nilai perusahaan. Hasil ini sesuai pula dengan penelitian 
sebelumnya yang dilakukan oleh Surifah (2017) dan Indriani (2014). Hasil uji T kedua untuk $\mathrm{Ha} 2$ dan Ha3 yaitu:

\begin{tabular}{|c|c|c|c|c|c|c|}
\hline \multicolumn{7}{|c|}{ Coefficients ${ }^{\mathrm{a}}$} \\
\hline \multirow[b]{2}{*}{ Model } & & \multicolumn{2}{|c|}{$\begin{array}{l}\text { Unstandardized } \\
\text { Coeff icients }\end{array}$} & \multirow{2}{*}{$\begin{array}{c}\text { Standardized } \\
\text { Coeff icients } \\
\text { Beta }\end{array}$} & \multirow[b]{2}{*}{$\mathrm{t}$} & \multirow[b]{2}{*}{ Sig. } \\
\hline & & $\mathrm{B}$ & Std. Error & & & \\
\hline \multirow[t]{7}{*}{1} & (Constant) & -2.202 & 1.165 & & -1.891 & .062 \\
\hline & Manajemen Laba & -22.197 & 22.143 & -.887 & -1.002 & .319 \\
\hline & Komisaris Independen & 1.617 & 1.593 & .100 & 1.015 & 313 \\
\hline & Komite Audit & 3.114 & .959 & .360 & 3.245 & .002 \\
\hline & Manajemen & & & & & \\
\hline & $\begin{array}{l}\text { Laba*Komisaris } \\
\text { Independen }\end{array}$ & -52.193 & 32.520 & -.834 & -1.605 & .112 \\
\hline & $\begin{array}{l}\text { Manajemen } \\
\text { Laba*Komite Audit }\end{array}$ & 37.160 & 18.229 & 1.566 & 2.039 & .045 \\
\hline
\end{tabular}

Berdasarkan tabel di atas dengan nilai sig. yang telah diketahui, dapat disimpulkan komisaris independen tidak memoderasi pengaruh manajemen laba terhadap nilai perusahaan. Hasil ini sesuai dengan penelitian Prasetyo (2017). Sedangkan komite audit memoderasi pengaruh manajemen laba terhadap nilai perusahaan. Hal ini sesuai dengan penelitian Prasetyo (2017) dan Kawatu (2009).

\section{KESIMPULAN}

Manajemen laba berpengaruh terhadap nilai perusahaan dan komite audit memoderasi pengaruh manajemen laba terhadap nilai perusahaan. Sedangkan komisaris independen tidak memoderasi pengaruh manajemen laba terhadap nilai perusahaan. Komisaris independen tidak memoderasi dapat terjadi karena pada beberapa perusahaan, komisaris independen berasal dari latar belakang yang berbeda-beda, yang memungkinkan keahlian dalam memonitor keputusan manajer keuangan, dalam memilih metode akuntansi dalam pengakuan laba, tidak ada atau lemah. Sedangkan komite audit berisi pihak dengan latar belakang yang paham dengan metode akuntansi dan pelaporan keuangan, sehingga memiliki peran penting dan berpengaruh dalam memonitor tindakan manajemen laba yang dapat memengaruhi nilai perusahaan. 


\section{DAFTAR PUSTAKA}

Darwis, Herman. (2012). Manajemen Laba terhadap Nilai Perusahaan dengan Corporate Governance sebagai Pemoderasi. Jurnal Keuangan dan Perbankan. Vol. 16 (1).

Fahmi, Irham. (2014). Manajemen Keuangan Perusahaan dan Pasar Modal. Jakarta: Mitra Wacana Media.

Ghozali, Imam. (2016). Aplikasi Analisis Multivariate dengan Program IBM SPSS 23. Semarang: BPFE Universitas Diponegoro.

Hamdani. (2016). Good Corporate Governance, Tinjauan Etika dalam Praktik Bisnis. Jakarta: Mitra Wacana Media.

Hayati, Annur Fitri dan Gusnardi. (2012). Pengaruh Penerapan Mekanisme Good Corporate Governance terhadap Manajemen Laba. Jurnal Akuntasi. Vol. 16 (03).

Herawaty, Vinola. (2008). Peran Praktek Good Corporate Governance sebagai Moderating Variable dari Pengaruh Earning Management terhadap Nilai Perusahaan. Jurnal Akuntansi dan Keuangan. Vol. 10 (2).

Ikatan Akuntansi Indonesia. (2004). Standar Akuntansi Keuangan. Jakarta: Salemba Empat.

Indriani, Poppy, Jaka Darmawan, dan Siti Nurhawa. (2014). Analisis Manajemen Laba terhadap Nilai Perusahaan yang terdaftar di Bursa Efek Indonesia. Jurnal Akuntansi dan Keuangan. Vol. 5 (1).

Kamil, Fauzan. (2014). Pengaruh Manajemen Laba terhadap Nilai Perusahaan dengan Mekanisme Corporate Governance sebagai Variabel Pemoderasi.

Kawatu, Freddy Semuel. (2009). Mekanisme Corporate Governance terhadap Nilai Perusahaan dengan Kualitas Laba sebagai Variabel Intervening. Jurnal Keuangan dan Perbankan. Vol. 13 (3).

Kumari, Prity dan J. K. Pattanayak. (2013). Impact of Corporate Governance on Level of Earnings Management and Overall Firm Performance: a Review. International Journal of Financial Management. Vol. 4 (1).

Marangu, Kenneth dan Ambrose Jagongo. (2014). Price to Book Value Ratio and Financial Statement Variables (an Empirical Study of Companies Quoted at Nairobi Securities Exchange, Kenya). Global Institute for Research and Education. Vol. 3 (6). NovemberDecember 2014.

Palestin, Halima Shatila. (2006). Analisis Pengaruh Struktur Kepemilikan, Praktik Corporate Governance, dan Kompensasi Bonus Terhadap Manajemen Laba.

Pearce II, John A. dan Richard B. Johnson, Jr. (2016). Strategic Management-Formulation, Implementation, and Control. Mcgraw Hill Education.

Putra, Cokorda Gde Bayu, Ni Ketut Rasmini, dan Ida Bagus Putra Astika. (2013). Pengaruh Corporate Social Responsibility pada Price to Book Value dengan Corporate Governance sebagai Variabel Moderasi.

Riadi, Edi. (2014). Metode Statistika Parametrik \& Nonparametrik: untuk Penelitian Ilmuilmu Sosial dan Pendidikan. Jakarta: Pustaka Mandiri

Scott, R. William. (2015). Financial Accounting Theory. $7^{\text {th }}$ edition. Pearson Prentice Hall: Toronto.

Surifah. (2017). The Role of Corporate Governance in The Effect Earnings Management has on Firm Value. Journal of Indonesian Economy and Business. Vol. 32 (1).

Wardiyah, Mia Lasmi. (2017). Analisis Laporan Keuangan. Bandung: CV Pustaka Setia. 